\title{
Supplement 1
}

Results of ANOVA tests performed to evaluate the differences in the long cell morphometry and wall thickness of $L$. corallioides collected in different sampling sites. Statistically significant $p$-values are given in bold. ANOVA test significance at $\alpha=0.05$; Tukey's test significant at $p \leq \alpha$. Any data transformation is indicated on the right side of the table

\begin{tabular}{|c|c|c|c|c|c|}
\hline \multicolumn{6}{|c|}{$\begin{array}{c}\text { One-way ANOVA test (Cell length) } \\
\text { Long cells } \\
\end{array}$} \\
\hline & Df & Sum sq. & Mean sq. & F value & $\operatorname{Pr}(>F)$ \\
\hline SITE & 4 & 0.230 & 0.057 & 68.590 & $\begin{array}{c}5.05 E- \\
11\end{array}$ \\
\hline Residuals & 19 & 0.016 & 0.001 & & \\
\hline \multicolumn{4}{|c|}{ Shapiro-Wilk normality test } & \multicolumn{2}{|l|}{$\mathrm{P}=0.109$} \\
\hline \multicolumn{4}{|c|}{ Bartlett's K-squared } & $\mathrm{P}=0.798$ & \\
\hline \multicolumn{6}{|c|}{$\begin{array}{c}\text { Tukey's test } \\
\text { Multiple comparisons of means }\end{array}$} \\
\hline \multirow{2}{*}{ SITE } & \multirow{2}{*}{$\begin{array}{c}\text { Mean } \\
\text { difference } \\
\text { SITE }\end{array}$} & \multicolumn{2}{|c|}{$\begin{array}{l}95 \% \text { confidence } \\
\text { interval }\end{array}$} & \multirow{2}{*}{\multicolumn{2}{|c|}{ P. adjusted }} \\
\hline & & $\begin{array}{l}\text { lower } \\
\text { bound }\end{array}$ & $\begin{array}{l}\text { upper } \\
\text { bound }\end{array}$ & & \\
\hline $\begin{array}{l}\text { Elba- } \\
\text { Egadi }\end{array}$ & -0.025 & -0.080 & 0.030 & & \\
\hline $\begin{array}{l}\text { Morlaix- } \\
\text { Egadi }\end{array}$ & 0.158 & 0.103 & 0.213 & & \\
\hline $\begin{array}{l}\text { Pontine- } \\
\text { Egadi }\end{array}$ & -0.152 & -0.211 & -0.094 & & \\
\hline $\begin{array}{l}\text { Santa } \\
\text { Caterina- } \\
\text { Egadi }\end{array}$ & -0.044 & -0.099 & 0.011 & & \\
\hline $\begin{array}{l}\text { Morlaix- } \\
\text { Elba }\end{array}$ & 0.183 & 0.128 & 0.238 & & \\
\hline $\begin{array}{l}\text { Pontine- } \\
\text { Elba }\end{array}$ & -0.128 & -0.186 & -0.069 & & \\
\hline $\begin{array}{l}\text { Santa } \\
\text { Caterina- } \\
\text { Elba }\end{array}$ & -0.019 & -0.074 & 0.036 & & \\
\hline $\begin{array}{l}\text { Pontine- } \\
\text { Morlaix }\end{array}$ & -0.311 & -0.369 & -0.252 & & \\
\hline $\begin{array}{l}\text { Santa } \\
\text { Caterina- } \\
\text { Morlaix }\end{array}$ & -0.202 & -0.257 & -0.147 & & \\
\hline $\begin{array}{l}\text { Santa } \\
\text { Caterina- } \\
\text { Pontine }\end{array}$ & 0.109 & 0.050 & 0.167 & & \\
\hline
\end{tabular}

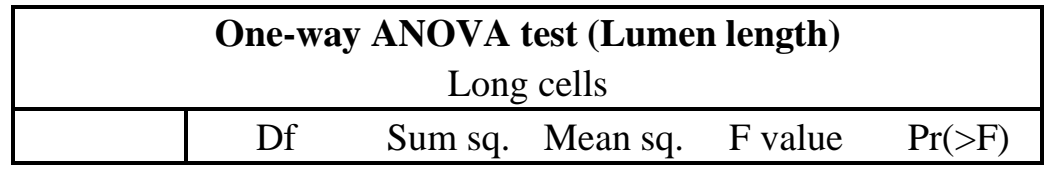




\begin{tabular}{|c|c|c|c|c|}
\hline \multirow{2}{*}{$\begin{array}{c}\text { SITE } \\
\text { Residuals }\end{array}$} & 4 & 0.312 & 0.078 & \multirow[t]{2}{*}{78.110} \\
\hline & 19 & 0.019 & 0.001 & \\
\hline \multicolumn{3}{|c|}{ Shapiro-Wilk normality test } & \multicolumn{2}{|r|}{$\mathrm{P}=0.097$} \\
\hline \multicolumn{3}{|c|}{ Bartlett's K-squared } & \multicolumn{2}{|r|}{$\mathrm{P}=0.846$} \\
\hline \multicolumn{5}{|c|}{$\begin{array}{c}\text { Tukey's test } \\
\text { Multiple comparisons of means }\end{array}$} \\
\hline \multirow{2}{*}{ SITE } & \multirow{2}{*}{$\begin{array}{c}\text { Mean } \\
\text { difference } \\
\text { SITE }\end{array}$} & \multicolumn{2}{|c|}{$\begin{array}{l}95 \% \text { confidence } \\
\text { interval }\end{array}$} & \multirow{2}{*}{ P. adjusted } \\
\hline & & $\begin{array}{l}\text { lower } \\
\text { bound }\end{array}$ & $\begin{array}{l}\text { upper } \\
\text { bound }\end{array}$ & \\
\hline $\begin{array}{l}\text { Elba- } \\
\text { Egadi }\end{array}$ & -0.010 & -0.070 & 0.050 & 0.985 \\
\hline $\begin{array}{l}\text { Morlaix- } \\
\text { Egadi }\end{array}$ & 0.181 & 0.121 & 0.241 & 0.000 \\
\hline $\begin{array}{l}\text { Pontine- } \\
\text { Egadi }\end{array}$ & -0.191 & -0.255 & -0.127 & 0.000 \\
\hline $\begin{array}{l}\text { Santa } \\
\text { Caterina- } \\
\text { Egadi }\end{array}$ & -0.021 & -0.081 & 0.039 & 0.831 \\
\hline $\begin{array}{l}\text { Morlaix- } \\
\text { Elba }\end{array}$ & 0.191 & 0.131 & 0.251 & 0.000 \\
\hline $\begin{array}{l}\text { Pontine- } \\
\text { Elba }\end{array}$ & -0.181 & -0.245 & -0.117 & 0.000 \\
\hline $\begin{array}{l}\text { Santa } \\
\text { Caterina- } \\
\text { Elba }\end{array}$ & -0.011 & -0.071 & 0.049 & 0.982 \\
\hline $\begin{array}{l}\text { Pontine- } \\
\text { Morlaix }\end{array}$ & -0.372 & -0.435 & -0.308 & 0.000 \\
\hline $\begin{array}{l}\text { Santa } \\
\text { Caterina- } \\
\text { Morlaix }\end{array}$ & -0.202 & -0.262 & -0.142 & 0.000 \\
\hline $\begin{array}{l}\text { Santa } \\
\text { Caterina- } \\
\text { Pontine }\end{array}$ & 0.170 & 0.106 & 0.234 & 0.000 \\
\hline
\end{tabular}

\begin{tabular}{|c|ccccc|}
\hline \multicolumn{5}{|c|}{ One-way ANOVA test (Cell sw) } \\
Long cells \\
\hline & Df & Sum sq. & Mean sq. & F value & $\operatorname{Pr}(>\mathrm{F})$ \\
\hline SITE & 4 & 1.790 & 0.447 & 7.207 & $\mathbf{1 . 0 5 E - 0 3}$ \\
Residuals & 19 & 1.180 & 0.062 & & \\
\hline Shapiro-Wilk normality test & $\mathrm{P}=0.362$ \\
\hline \multicolumn{5}{|c|}{ Bartlett's K-squared } & $\mathrm{P}=0.068$ \\
\hline \multicolumn{5}{|c|}{ Tukey's test } \\
\hline \multirow{5}{*}{ SITE } & $\begin{array}{c}\text { Multiple comparisons of means } \\
\text { difference }\end{array}$ & $\begin{array}{c}\text { 95\% confidence } \\
\text { interval }\end{array}$ & \multirow{2}{*}{ P. adjusted } \\
\hline
\end{tabular}




\begin{tabular}{|c|c|c|c|c|}
\hline & SITE & $\begin{array}{l}\text { lower } \\
\text { bound }\end{array}$ & $\begin{array}{l}\text { upper } \\
\text { bound }\end{array}$ & \\
\hline $\begin{array}{l}\text { Elba- } \\
\text { Egadi }\end{array}$ & 0.347 & -0.127 & 0.821 & 0.222 \\
\hline $\begin{array}{l}\text { Morlaix- } \\
\text { Egadi }\end{array}$ & -0.165 & -0.639 & 0.309 & 0.830 \\
\hline $\begin{array}{l}\text { Pontine- } \\
\text { Egadi }\end{array}$ & 0.487 & -0.016 & 0.990 & 0.060 \\
\hline $\begin{array}{l}\text { Santa } \\
\text { Caterina- } \\
\text { Egadi }\end{array}$ & 0.517 & 0.043 & 0.991 & 0.028 \\
\hline $\begin{array}{l}\text { Morlaix- } \\
\text { Elba }\end{array}$ & -0.512 & -0.986 & -0.038 & $\mathbf{0 . 0 3 0}$ \\
\hline $\begin{array}{l}\text { Pontine- } \\
\text { Elba }\end{array}$ & 0.140 & -0.362 & 0.643 & 0.915 \\
\hline $\begin{array}{l}\text { Santa } \\
\text { Caterina- } \\
\text { Elba }\end{array}$ & 0.170 & -0.304 & 0.644 & 0.814 \\
\hline $\begin{array}{l}\text { Pontine- } \\
\text { Morlaix }\end{array}$ & 0.652 & 0.150 & 1.155 & 0.008 \\
\hline $\begin{array}{l}\text { Santa } \\
\text { Caterina- } \\
\text { Morlaix }\end{array}$ & 0.682 & 0.208 & 1.156 & 0.003 \\
\hline $\begin{array}{l}\text { Santa } \\
\text { Caterina- } \\
\text { Pontine }\end{array}$ & 0.030 & -0.473 & 0.533 & 1.000 \\
\hline
\end{tabular}


Results of ANOVA tests performed to evaluate the differences in the short cell morphometry and wall thickness of $L$. corallioides collected in different sampling sites. Statistically significant $p$-values are given in bold. ANOVA test significance at $\alpha=0.05$; Tukey's test significant at $p \leq \alpha$. Any data transformation is indicated on the right side of the table.

\begin{tabular}{|c|c|c|c|c|c|}
\hline \multicolumn{6}{|c|}{$\begin{array}{c}\text { One-way ANOVA test (Lumen length) } \\
\text { Short cells } \\
\end{array}$} \\
\hline & Df & Sum sq. & Mean sq. & F value & $\operatorname{Pr}(>\mathrm{F})$ \\
\hline SITE & 4 & 145.453 & 36.363 & 30.573 & $\begin{array}{l}4.86 \mathrm{E}- \\
08\end{array}$ \\
\hline Residuals & 19 & 22.598 & 1.189 & & \\
\hline \multicolumn{4}{|c|}{ Shapiro-Wilk normality test } & \multicolumn{2}{|l|}{$\mathrm{P}=0.122$} \\
\hline \multicolumn{4}{|c|}{ Bartlett's K-squared } & \multicolumn{2}{|l|}{$\mathrm{P}=0.118$} \\
\hline \multicolumn{6}{|c|}{$\begin{array}{c}\text { Tukey's test } \\
\text { Multiple comparisons of means }\end{array}$} \\
\hline \multirow{2}{*}{ SITE } & \multirow{2}{*}{$\begin{array}{c}\text { Mean } \\
\text { difference } \\
\text { SITE }\end{array}$} & \multicolumn{2}{|c|}{$\begin{array}{l}95 \% \text { confidence } \\
\text { interval }\end{array}$} & \multirow{2}{*}{\multicolumn{2}{|c|}{ P. adjusted }} \\
\hline & & $\begin{array}{l}\text { lower } \\
\text { bound }\end{array}$ & $\begin{array}{l}\text { upper } \\
\text { bound }\end{array}$ & & \\
\hline $\begin{array}{l}\text { Elba- } \\
\text { Egadi }\end{array}$ & 3.122 & 1.048 & 5.196 & & \\
\hline \begin{tabular}{|l|} 
Morlaix- \\
Egadi
\end{tabular} & 3.907 & 1.833 & 5.982 & & \\
\hline $\begin{array}{l}\text { Pontine- } \\
\text { Egadi }\end{array}$ & -3.281 & -5.481 & -1.081 & & \\
\hline \begin{tabular}{|l|} 
Santa \\
Caterina- \\
Egadi
\end{tabular} & 0.313 & -1.761 & 2.387 & & \\
\hline $\begin{array}{l}\text { Morlaix- } \\
\text { Elba }\end{array}$ & 0.785 & -1.289 & 2.859 & & \\
\hline $\begin{array}{l}\text { Pontine- } \\
\text { Elba }\end{array}$ & -6.404 & -8.604 & -4.203 & & \\
\hline \begin{tabular}{|l} 
Santa \\
Caterina- \\
Elba
\end{tabular} & -2.809 & -4.883 & -0.735 & & \\
\hline $\begin{array}{l}\text { Pontine- } \\
\text { Morlaix }\end{array}$ & -7.189 & -9.389 & -4.989 & & \\
\hline \begin{tabular}{|l|} 
Santa \\
Caterina- \\
Morlaix
\end{tabular} & -3.594 & -5.668 & -1.520 & & \\
\hline \begin{tabular}{|l|} 
Santa \\
Caterina- \\
Pontine
\end{tabular} & 3.595 & 1.394 & 5.795 & & \\
\hline
\end{tabular}

\begin{tabular}{|c|ccccc|}
\multicolumn{6}{|c|}{ Short cells } \\
\hline & Df & Sum sq. & Mean sq. & F value & $\operatorname{Pr}(>\mathrm{F})$ \\
\hline SITE & 4 & 0.053 & 0.013 & 1.138 & $7.64 \mathrm{E}-02$
\end{tabular}




\begin{tabular}{|c|ccc|} 
Residuals & $19 \quad 0.222$ & 0.012 & \\
\hline Shapiro-Wilk normality test & $\mathrm{P}=0.069$ \\
\hline Bartlett's K-squared & $\mathrm{P}=0.589$ \\
\hline
\end{tabular}

\begin{tabular}{|c|c|c|c|c|}
\hline \multicolumn{5}{|c|}{$\begin{array}{l}\text { One-way ANOVA test (Cell pw) } \\
\text { Short cells }\end{array}$} \\
\hline & Df & Sum sq. & Mean sq. & F value \\
\hline SITE & 4 & 1.312 & 0.328 & \multirow[t]{2}{*}{$10.090 \quad$ 1.82E-04 } \\
\hline Residuals & 18 & 0.585 & 0.033 & \\
\hline \multicolumn{4}{|c|}{ Shapiro-Wilk normality test } & $\mathrm{P}=0.646$ \\
\hline \multicolumn{4}{|c|}{ Bartlett's K-squared } & $P=0.208$ \\
\hline \multicolumn{5}{|c|}{$\begin{array}{c}\text { Tukey's test } \\
\text { Multiple comparisons of means }\end{array}$} \\
\hline \multirow{2}{*}{ SITE } & \multirow{2}{*}{$\begin{array}{c}\text { Mean } \\
\text { difference } \\
\text { SITE }\end{array}$} & \multicolumn{2}{|c|}{$\begin{array}{l}\text { 95\% confidence } \\
\text { interval }\end{array}$} & \multirow{2}{*}{ P. adjusted } \\
\hline & & $\begin{array}{l}\text { lower } \\
\text { bound }\end{array}$ & $\begin{array}{l}\text { upper } \\
\text { bound }\end{array}$ & \\
\hline $\begin{array}{l}\text { Elba- } \\
\text { Egadi }\end{array}$ & -0.211 & -0.556 & 0.133 & 0.375 \\
\hline $\begin{array}{l}\text { Morlaix- } \\
\text { Egadi }\end{array}$ & -0.245 & -0.590 & 0.099 & 0.242 \\
\hline $\begin{array}{l}\text { Pontine- } \\
\text { Egadi }\end{array}$ & 0.346 & -0.020 & 0.712 & 0.069 \\
\hline $\begin{array}{l}\text { Santa } \\
\text { Caterina- } \\
\text { Egadi }\end{array}$ & -0.373 & -0.739 & -0.008 & 0.044 \\
\hline $\begin{array}{l}\text { Morlaix- } \\
\text { Elba }\end{array}$ & -0.034 & -0.379 & 0.311 & 0.998 \\
\hline $\begin{array}{l}\text { Pontine- } \\
\text { Elba }\end{array}$ & 0.558 & 0.192 & 0.923 & 0.002 \\
\hline $\begin{array}{l}\text { Santa } \\
\text { Caterina- } \\
\text { Elba }\end{array}$ & -0.162 & -0.528 & 0.204 & 0.672 \\
\hline $\begin{array}{l}\text { Pontine- } \\
\text { Morlaix }\end{array}$ & 0.592 & 0.226 & 0.957 & 0.001 \\
\hline $\begin{array}{l}\text { Santa } \\
\text { Caterina- } \\
\text { Morlaix }\end{array}$ & -0.128 & -0.494 & 0.238 & 0.825 \\
\hline $\begin{array}{l}\text { Santa } \\
\text { Caterina- } \\
\text { Pontine }\end{array}$ & -0.719 & -1.105 & -0.334 & 0.000 \\
\hline
\end{tabular}


Results of Kruskal-Wallis test performed to evaluate the differences in the cell length of $L$. corallioides collected in different sampling sites. Test significance at $\alpha=0.05$

\begin{tabular}{|c|c|c|c|c|}
\hline \multirow{2}{*}{\multicolumn{5}{|c|}{$\begin{array}{c}\text { Kruskal-Wallis test (Cell length) } \\
\text { Short cells }\end{array}$}} \\
\hline & & & & \\
\hline \multicolumn{5}{|c|}{ of $\quad \chi^{2}$} \\
\hline SITE & 4 & \begin{tabular}{|lc} 
& 16.468 \\
\end{tabular} & & 0.002 \\
\hline \multicolumn{5}{|c|}{$\begin{array}{l}\text { Dunn's test } \\
\text { Comparisons by SITE (Bonferroni) }\end{array}$} \\
\hline $\begin{array}{c}Z \\
P . \\
\text { adjusted }\end{array}$ & Egadi & Elba & Morlaix & Pontine \\
\hline Elba & $\begin{array}{c}0.537826 \\
1\end{array}$ & & & \\
\hline Morlaix & -0.35855 & $\begin{array}{c}-0.89638 \\
1\end{array}$ & & \\
\hline Pontine & $\begin{array}{l}3.063535 \\
\mathbf{0 . 0 1 0 9}\end{array}$ & $\begin{array}{c}2.556467 \\
0.0529\end{array}$ & $\begin{array}{c}3.40158 \\
\mathbf{0 . 0 0 3 3}\end{array}$ & \\
\hline Santa & 2.061669 & 1.523842 & 2.42022 & -1.11978 \\
\hline Caterina & 0.1962 & 0.6377 & 0.0776 & 1 \\
\hline
\end{tabular}


Statistical correlations were used to evaluate the relationship between each morphological and calcification parameter measured in the long cells of $L$. corallioides. Test significance at $p<0.05$.

\begin{tabular}{|c|c|c|c|}
\hline correlation & Long & cells & $p$-value \\
\hline Spearman's & cell.length & lumen.length & $<0.05$ \\
\hline Spearman's & cell.sw & lumen.length & $<0.05$ \\
\hline Spearman's & cell.length & cell.diameter & $>0.05$ \\
\hline Spearman's & cell.length & cell.sw & $<0.05$ \\
\hline Spearman's & cell.pw & cell.sw & $<0.05$ \\
\hline Spearman's & lumen.diameter & lumen.length & $<0.05$ \\
\hline Pearson's & lumen.diameter & cell.diameter & $<0.05$ \\
\hline Pearson's & cell.sw & lumen.diameter & $<0.05$ \\
\hline Pearson's & cell.sw & cell.diameter & $>0.05$ \\
\hline
\end{tabular}
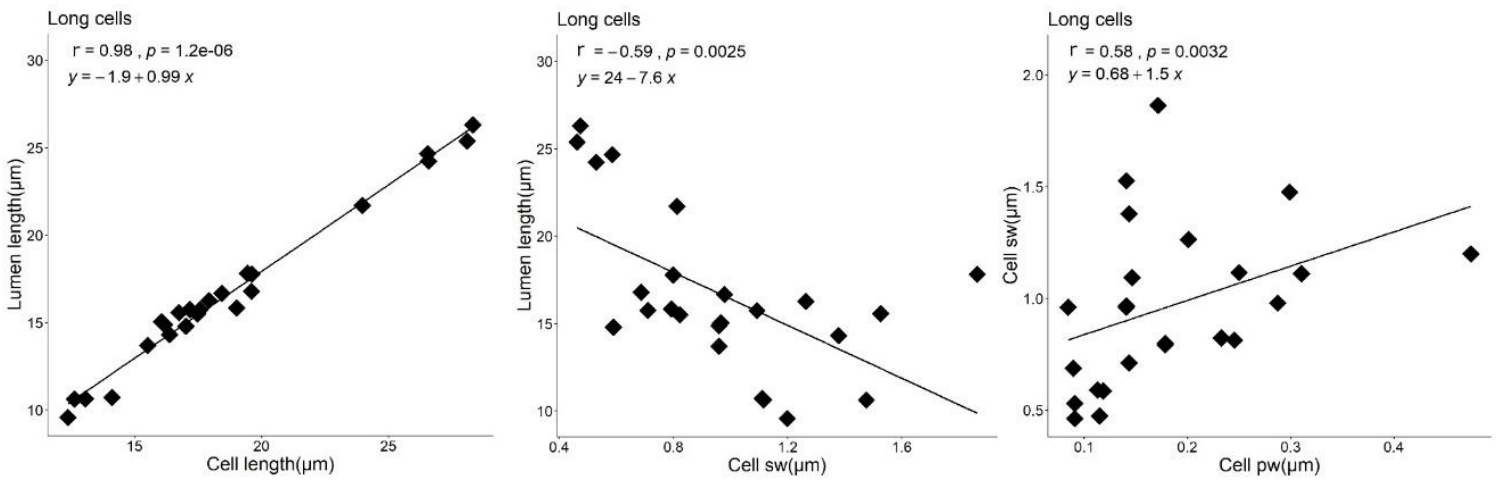
Statistical correlations were used to evaluate the relationship between each morphological and calcification parameter measured in the long cells of $L$. corallioides. Test significance at $p<0.05$.

\begin{tabular}{l|l|l|l}
\hline \multicolumn{1}{c|}{ correlation } & \multicolumn{2}{c|}{ Short cells } & $p$-value \\
\hline Pearson's & cell.length & lumen.length & $<\mathbf{0 . 0 5}$ \\
\hline Spearman's & cell.sw & lumen.length & $>0.05$ \\
\hline Pearson's & cell.length & cell.diameter & $>0.05$ \\
\hline Spearman's & cell.length & cell.sw & $>0.05$ \\
\hline Spearman's & cell.pw & cell.sw & $>0.05$ \\
\hline Pearson's & lumen.diameter & lumen.length & $<\mathbf{0 . 0 5}$ \\
\hline Pearson's & lumen.diameter & cell.diameter & $>0.05$ \\
\hline Spearman's & cell.sw & lumen.diameter & $>0.05$ \\
\hline Spearman's & cell.sw & cell.diameter & $>0.05$ \\
\hline
\end{tabular}

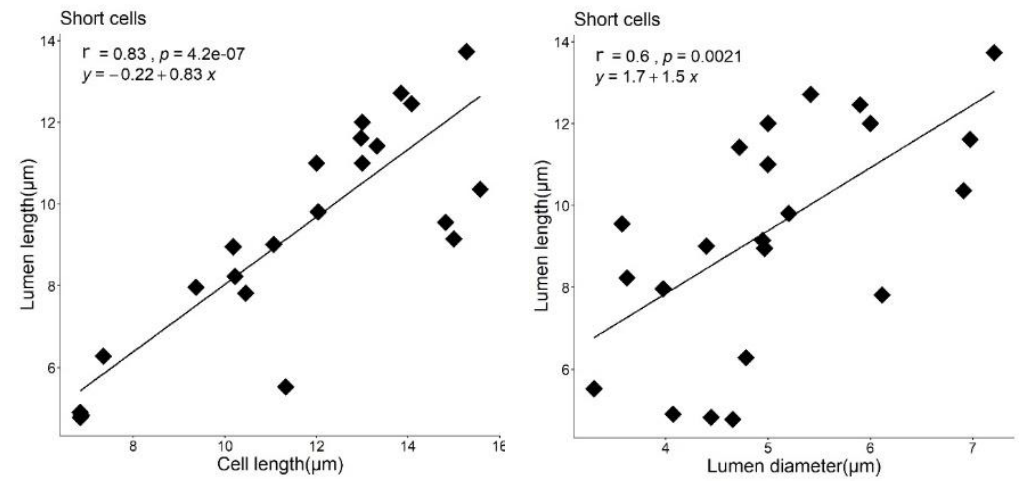

